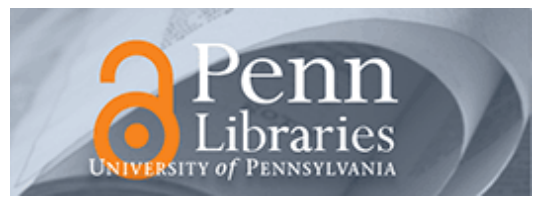

University of Pennsylvania

ScholarlyCommons

Operations, Information and Decisions Papers

Wharton Faculty Research

$2-2012$

\title{
Walking the Talk in Multiparty Bargaining: An Experimental Investigation
}

\author{
Kathleen L. McGinn \\ Katherine L. Milkman \\ University of Pennsylvania \\ Markus Noth
}

Follow this and additional works at: https://repository.upenn.edu/oid_papers

Part of the Other Business Commons, and the Other Communication Commons

\section{Recommended Citation}

McGinn, K. L., Milkman, K. L., \& Noth, M. (2012). Walking the Talk in Multiparty Bargaining: An

Experimental Investigation. Journal of Economic Psychology, 33 (1), 278-291. http://dx.doi.org/10.1016/ j.joep.2011.10.008

This paper is posted at ScholarlyCommons. https://repository.upenn.edu/oid_papers/29

For more information, please contact repository@pobox.upenn.edu. 


\title{
Walking the Talk in Multiparty Bargaining: An Experimental Investigation
}

\author{
Abstract \\ We study the framing effects of communication on payoffs in multiparty bargaining. Communication has \\ been shown to be more truthful and revealing than predicted in equilibrium. Because talk is preference- \\ revealing, it may effectively frame bargaining around a logic of fairness or competition, moving parties on \\ a path toward or away from equal-division agreements. These endogenous framing effects may outweigh \\ any overall social utility effects due to the mere presence of communication. In two studies, we find that \\ non-binding talk about fairness within a three-party, complete-information game leads toward off- \\ equilibrium, equal division payoffs, while non-binding talk focusing on Competitive Reasoning moves \\ parties away from equal divisions. Our two studies allow us to demonstrate that manipulated pre-game \\ talk and spontaneous within-game dialogue lead to the same results. \\ Keywords \\ communication, fairness, bargaining, negotiations \\ Disciplines \\ Other Business | Other Communication
}


H A R VAR D

Walking the Talk in Multiparty Bargaining: An Experimental Investigation

Kathleen L. McGinn

Katherine L. Milkman

Markus Nöth

\section{Working Paper}

10-039 


\title{
Walking the Talk in Multiparty Bargaining: An Experimental Investigation
}

\author{
Kathleen L. McGinn (corresponding author) \\ Harvard Business School, Harvard University, Soldiers Field Road, Boston, MA 02163, USA \\ kmcginn@hbs.edu, p: 00-1-617-495 6901,f: 00-1-617-496-4191 \\ Katherine L. Milkman \\ Wharton School, University of Pennsylvania, 3730 Walnut Street, Philadelphia, PA 19104, USA \\ kmilkman@wharton.upenn.edu \\ Markus Nöth \\ Universität Hamburg, Von-Melle-Park 5, 20146 Hamburg, Germany \\ markus.noeth@uni-hamburg.de
}

\begin{abstract}
We study the framing effects of communication in multiparty bargaining. Communication has been shown to be more truthful and revealing than predicted in equilibrium. Because talk is preferencerevealing, it may effectively frame bargaining around a logic of fairness or competition, moving parties on a path toward or away from equal-division agreements. These endogenous framing effects may outweigh any overall social utility effects due to the mere presence of communication. In two experiments, we find that non-binding talk of fairness within a three-party, complete-information game leads toward off-equilibrium, equal division payoffs, while non-binding talk focusing on competitive reasoning moves parties away from equal divisions. Our two studies allow us to demonstrate that spontaneous within-game dialogue and manipulated pre-game talk lead to the same results.
\end{abstract}

Key words: communication; fairness; bargaining

JEL codes: C72, C78, D03, D74 


\title{
Walking the Talk in Multiparty Bargaining: An Experimental Investigation
}

\begin{abstract}
We study the framing effects of communication in multiparty bargaining. Communication has been shown to be more truthful and revealing than predicted in equilibrium. Because talk is preferencerevealing, it may effectively frame bargaining around a logic of fairness or competition, moving parties on a path toward or away from equal-division agreements. These endogenous framing effects may outweigh any overall social utility effects due to the mere presence of communication. In two experiments, we find that non-binding talk of fairness within a three-party, complete-information game leads toward off-equilibrium, equal division payoffs, while non-binding talk focusing on competitive reasoning moves parties away from equal divisions. Our two studies allow us to demonstrate that spontaneous within-game dialogue and manipulated pre-game talk lead to the same results.
\end{abstract}

Key words: communication; fairness; bargaining

JEL codes: C72, C78, D03, D74 


\section{Introduction}

Communication between parties materially affects the distribution of resources in bargaining. In bargaining games with complete information, non-binding pre-game talk enhances cooperation (Demichelis and Weibull, 2008). In games with private information, communication facilitates the exchange of information, allowing coordination on a mutually agreeable focal point and increasing the likelihood of agreement (Valley, Thomson, Gibbons and Bazerman, 2002). Past research has established that the mere presence of communication increases cooperative behavior in bargaining (Sally, 1995).

Standard equilibrium predictions in multiparty bargaining games assume competitive forces will drive bargaining behavior, resulting in payoffs reflecting parties' resources or alternatives outside of negotiations (Nash, 1951; Von Neumann and Morgenstern, 1953). Research on fairness offers an alternative point of view from which to examine bargaining behavior and payoffs (Kahneman, Knetsch and Thaler, 1986, Bolton and Ockenfels, 2000). Experimental studies of bilateral bargaining and public goods games reveal that negotiated agreements often conform to fairness norms as much as or more than they conform to competitive, game-theoretic predictions (Prasnikar and Roth, 1992; Frey and Meier, 2004; Hoffman, McCabe and Smith, 1996). Communication appears to heighten attention to fairness norms by allowing the transmission of private information to reveal distribution symmetry (Crawford and Sobel, 1982; Roth and Malouf, 1979) and providing parties with an opportunity to raise fairness concerns. Communication may, however, introduce norms other than fairness in bargaining (Bohnet and Frey, 1999); talk may sometimes lead to fair outcomes but other times may lead to payoffs based on other rationalizable distribution criteria (Farrell, 1988). We study the ways in which the content of talk allows parties to bargain "on what they should all agree is the right thing to do" (Charness and Dufwenberg, 2006: 1595) - sometimes they may agree to aim for a "fair" outcome and sometimes a competitive one.

There are various definitions of fairness, but many bargaining studies have operationalized the "fair outcome" as an equal distribution of available surplus (for empirical evidence, see Güth, Ockenfels and Tietz, 1990; Young, 1993; Brams and Taylor, 1996). This is the definition we adopt in our two experiments. We limit our exploration of equal division of payoffs to multiparty bargaining games with 
complete information. In our first study we place no restrictions on verbal communication in bargaining, code naturally arising talk by type, and analyze the effects of communication content on equality of payoffs. We rely on previously uncoded and unanalyzed communication data from a bargaining experiment conducted by Croson, Gomes, McGinn and Nöth (2004). ${ }^{1}$ In our second study we experimentally manipulate the content of pre-game talk to test whether the type of talk affects the distribution of surplus in the subsequent bargaining game with unrestricted communication. We hypothesize that the effects of communication on multiparty bargaining payoffs will depend on whether talk frames bargaining around a logic of fairness or a logic of competition.

Across both studies, we find that the effects of communication go beyond simply increasing cooperation as suggested by past research. All talk is not created equal - some talk moves parties closer to equal distributions, while other talk moves parties away from equal division of surplus. The content of communication shapes outcomes by priming interactions around a logic for exchange - fair or competitive - thereby affecting the likelihood of efficiency maximizing transfers and the equality of payoffs across parties. Pre-game communication manipulated to prime a fairness frame drives parties to divide surpluses more evenly than pre-game communication manipulated to prime a competitive frame.

This paper proceeds as follows. Section 2 reviews past research on the role of communication in bargaining games and discusses the mechanisms through which different types of communication may affect the outcomes of multiparty bargaining with complete information. Section 3 summarizes the design of the Croson et al. (2004) experiments that produced the communication data analyzed in Study 1 and introduces the procedures we followed for coding verbal communications. We also present our Study 1 results in Section 3, along with robustness checks to further explore how communication affects outcomes. Section 4 describes the design of and results from Study 2. We conclude in Section 5 with a summary of our findings and a discussion of their implications.

\footnotetext{
${ }^{1}$ Croson et al. (2004) use payoff data to test the relative predictive power of three equilibrium models: the Nucleolus (Schmeidler, 1969), the Shapley value (Shapley, 1953), and the Coalitional Bargaining Value (CBV) (Gomes, 2005). Capturing all communication was a byproduct of the study. We requested and obtained the communication and payoff data from the authors.
} 


\section{Communication in Bargaining}

Marshall (1969) described economic exchange as "bargaining supplemented by custom and by notions of fairness". Supporting this social view, a plethora of research has documented preferences for fairness in economic transactions. Kahneman, Knetsch and Thaler's seminal paper (1986) reports on household surveys in which respondents' preferences reflected concerns for fair treatment across multiple market domains. Critical to the question addressed here, the survey responses revealed that fairness was evaluated relative to a stated referent, rather than according to some absolute standard.

Past research on two-party bargaining suggests that communication may heighten fairness concerns in preferences and actions. The possible role for communication in triggering fair outcomes in bargaining varies with the presence or absence of private information. In games with private information, communication allows the revelation of information that makes payoff comparisons possible (Roth and Malouf, 1979). Games with complete information eliminate the informational advantages of communication, but empirical evidence suggests that communication continues to play a powerful role nonetheless (e.g., Crawford, 1998; Farrell, 1998; Farrell and Rabin, 1996; Orbell, van de Kragt and Dawes, 1988; Sally, 1995; Rabin, 1994). Rabin (1990) shows that coordination need not be restricted to equilibrium outcomes if the communication is rationalizable, i.e., if the communication is plausible given the self-interest of the party talking.

While much of the prior research on communication in bargaining suggests that the mere presence of communication leads toward equal payoffs (Kachelmeier and Towry, 2002), an increasingly vocal chorus suggests that communication effects are more variable. Communication may prime multiparty bargaining by influencing the emergence of a dominant, shared frame for interactions, illuminating alternative paths to specific types of agreements (Bohnet and Frey, 1999; Blume and Ortmann, 2007). When players hold a common understanding of the message conveyed through communication, behavior and expectations of that behavior will be consistent with the content of the messages (Dimichelis and Weibull, 2008; Rabin, 1993). The generalized notion emerging from these models is that people behave in a way that is consistent with the motives or behavior they ascribe to other 
parties and that ascription can be driven by communication. If this is the mechanism through which communication affects outcomes, "mere" talk will not reliably increase the likelihood of fair outcomes.

The social psychological literature on priming (see Higgins and Bargh, 1987, for review of this literature) reinforces the notion that talk establishes beliefs about the nature of an interaction, driving bargaining behavior and outcomes. For example, Liberman, Samuels and Ross (2004) found that priming different norms in a prisoner's dilemma game by calling it "The Wall Street Game" (a competitive prime) in one treatment and "The Community Game" (a collaborative prime) in another treatment markedly changed the behavior of subjects. Defection was significantly higher in "The Wall Street Game" than in the (economically identical) "Community Game." Similarly, Robert and Carnevale (1997) primed either a "fairness" or a "rational" frame through written instructions and found the predicted effects on the generosity of individuals' ultimatum offers.

The role communication may play in affecting the equality of distributions in multiparty bargaining is complicated by the potential for coalitions. We are aware of three previous studies that have gathered communication data in three-party bargaining contexts. Bolton, Chatterjee and McGinn (2003) study a three-party coalition game in which the grand coalition, but not an equal division of available resources, is predicted in equilibrium. The presence of communication materially affected payoffs. Equal splits occurred frequently between parties engaging in private communication. These authors mention that fairness is offered as a rationale for outcomes in over one-third of the bargaining transcripts, but provide no further analysis of communication effects. Croson et al. (2004) permitted communication in their study of three-firm takeover negotiations but did not explore the effect of talk on outcomes. Finally, Bolton and Brosig (2007) found that payoffs in a three-party coalition game were consistently closer to equal when the parties communicated prior to coming to agreement. Although both of the Bolton studies link communication with more equal divisions of available surplus, neither of these studies examines how communication may move parties toward an equal division of surplus.

Work on priming, noted above, suggests that talk specifically eliciting fairness concerns should move outcomes toward an equal distribution of available resources. Conversely, talk highlighting 
bargaining power or resource asymmetries should move outcomes toward competitive payoffs. Isolating the specific way in which communication moves outcomes toward, or away from, more equal distributions of resources requires an analysis of the connection between communication content and bargaining outcomes. This is the approach we take in the studies described below. The type of talk subjects engage in during multiparty bargaining with complete information should prime participants to think of the interaction differently and thus take different paths to agreement. Our studies test the proposition that communication concerning fairness will move agreements toward an equal distribution of surplus, while communication concerning competitive reasoning will move agreements away from an equal distribution of surplus. Study 1 allows unrestricted communication within the bargaining game. In Study 2 , we exogenously manipulate pre-game communication followed by unrestricted within-game communication.

\section{Study 1}

\subsection{Experimental Design}

We study bargaining situations involving three parties. Two-way and three-way agreements are possible. Three parties can reach a three-way agreement in one step or in two steps with an initial two-way agreement followed by a second agreement. In two-way agreements, the excluded party's payoffs are affected through (sometimes positive and sometimes negative) externalities resulting from the other parties' deal.

The bargaining context studied by Croson et al. (2004) was designed to loosely resemble takeover markets. These markets vary in terms of the benefits of and externalities from merger activities. A merger may affect all parties in an industry, as well as those involved in a merger agreement. Five different sets of payoff parameters in Croson et al. (2004) reflect economic differences across industries. Variation in payoffs predicted in standard equilibrium models, exists across the different parameter settings. 
The game in Study 1 is described with the following notation: Stand-alone payoffs for firms, A, B and $\mathrm{C}$, are denoted as $\mathrm{V}_{\mathrm{A}}, \mathrm{V}_{\mathrm{B}}$, and $\mathrm{V}_{\mathrm{C}}$ respectively. The values of the merged companies, $\mathrm{AB}, \mathrm{AC}$ and $\mathrm{BC}$, are denoted as $\mathrm{V}_{\mathrm{AB}}, \mathrm{V}_{\mathrm{AC}}$ and $\mathrm{V}_{\mathrm{BC}}$, respectively. The value of the three-way firm, $\mathrm{ABC}$, is denoted as $\mathrm{V}_{\mathrm{ABC}}$, where $\left(\mathrm{V}_{\mathrm{ABC}}>\mathrm{V}_{\mathrm{AB}}, \mathrm{V}_{\mathrm{AC}}, \mathrm{V}_{\mathrm{BC}}\right)$. The values of mergers and externalities across the five treatments are presented in Table 1. The presence of five different treatments allows us to show that our communication results are not driven by a single set of payoff parameters. ${ }^{2}$

\begin{tabular}{|c|c|c|c|c|c|c|c|c|c|c|c|c|}
\hline & \multirow{3}{*}{$\begin{array}{c}\text { \# of } \\
\text { Subjects }\end{array}$} & \multirow{3}{*}{ Negotiations } & \multicolumn{10}{|c|}{ Outcome } \\
\hline & & & \multicolumn{3}{|c|}{ A, B, C Separate } & \multicolumn{2}{|c|}{$\begin{array}{c}\text { A, B Merge, } \\
\text { C Separate }\end{array}$} & \multicolumn{2}{|c|}{$\begin{array}{c}\text { A, C Merge, } \\
\text { B Separate }\end{array}$} & \multicolumn{2}{|c|}{$\begin{array}{c}\text { B, C Merge, } \\
\text { A Separate }\end{array}$} & \multirow{2}{*}{$\frac{\text { A, B, C Merge }}{\mathbf{V}_{\mathrm{ABC}}}$} \\
\hline & & & $\mathbf{V}_{\mathbf{A}}$ & $\mathbf{V}_{\mathbf{B}}$ & $\mathbf{V}_{\mathrm{C}}$ & $\mathbf{V}_{\mathrm{AB}}$ & $\mathbf{V}_{\mathrm{C}}$ & $\mathbf{V}_{\mathrm{AC}}$ & $\mathbf{V}_{\mathbf{B}}$ & $\mathbf{V}_{\mathrm{BC}}$ & $\mathbf{V}_{\mathbf{A}}$ & \\
\hline Treatment 1 & 24 & 40 & 50 & 50 & 50 & 300 & 50 & 300 & 50 & 150 & 50 & 400 \\
\hline Treatment 2 & 18 & 30 & 0 & 0 & 0 & 130 & 0 & 5 & 0 & 5 & 0 & 400 \\
\hline Treatment 4 & 21 & 35 & 100 & 100 & 100 & 230 & 50 & 220 & 70 & 210 & 160 & 400 \\
\hline Treatment 5 & 27 & 45 & 100 & 100 & 100 & 220 & 20 & 220 & 150 & 210 & 140 & 400 \\
\hline Treatment 6 & 27 & 44 & 50 & 50 & 50 & 240 & 140 & 210 & 150 & 180 & 180 & 400 \\
\hline
\end{tabular}

\subsection{Experimental Procedures}

The data were collected in the Computer Lab for Experimental Research at Harvard Business School. One hundred and seventeen members of the standing subject pool were recruited through advertisements in multiple Boston-area campus newspapers. Each participant was randomly assigned to one role within one session and played five rounds within a single treatment. This resulted in 194 observations of three-party bargaining games.

Subjects rotated across rounds to ensure that no participant encountered the same player in more than one round. Participants were not told how many rounds they would play. Sessions lasted 90 to 120 minutes. Aside from the unique payoff parameters for each treatment (see Table 1), procedures were identical across sessions. Payoffs in each round were independent, i.e. there were no carryovers across rounds. To avoid wealth effects, participants were paid based on their earnings in a single, randomly selected round (US\$0.11 for each point earned), plus a base rate of US\$15. Actual incentive pay ranged from US\$0 to US\$27.50.

\footnotetext{
${ }^{2}$ The communication data of treatment 3 was lost due to a hardware failure.
} 
The software connecting the three players for a given round was programmed with a single screen interface. ${ }^{3}$ This screen included a box for formal offers, buttons for accepting and rejecting offers, a text box for all other communication, and a box with complete payoff information, including the game parameters and the payoffs for current offers and all previously accepted offers. All information on the screen, including offers and written communication, was public information (a sample screen is provided in the Appendix).

There were two forms of communication available to the participants throughout each round: non-binding written messages and binding offers. Within the text box, participants could write anything they wanted with the exception of identifying information. Otherwise, there were no constraints put on messages. To make an offer, a party selected one or both of the other parties to be included in the agreement and specified the payment(s) being offered to each of the included parties. Only the included party(ies) could accept or reject an offer. Offers remained open for 15 seconds and were then automatically withdrawn. Only one offer could be open at a time. Accepted offers were binding. If a three-way offer was accepted, the negotiation ended. If a two-way offer was accepted and one party still remained independent, bargaining could continue, allowing for the possibility of a subsequent agreement. The seller in the first accepted deal was no longer involved in bargaining. He or she could see all subsequent interactions but could not input messages or offers. A round ended when all three firms consolidated or when the ten-minute time limit was reached.

\subsection{Paths to agreement}

As a result of the game's design, the negotiations in this study can follow one of four possible paths: (1) the parties reach a 3-way agreement in one step (direct 3-way agreement), (2) two parties reach an agreement and the buyer then comes to a subsequent agreement with the third party (3-way agreement following 2-way agreement), (3) two parties reach an exclusive agreement (2-way agreement), or (4) no agreement is reached (no agreement). Across the 194 negotiations in this experiment, we observe 101

\footnotetext{
3 This software was designed and programmed by C. Nicholas McKinney, Rhodes College, Department of Economics and Business Administration.
} 
direct 3-way agreements (52.1\%), 75 3-way agreements following 2-way agreements (38.7\%), 14 2-way agreements (7.2\%) and 4 impasses (2.1\%).

In games that end with direct 3-way agreements and in games that end with an impasse, there is only a single stage of negotiation, which we refer to as "Stage 1". However, in games that begin with a two-way merger, there are two stages of negotiation - a first stage that takes place before the two-way merger, which we refer to as "Stage 1", and a second stage that takes place after the two-way merger, which we refer to as "Stage 2". We analyze talk in the overall negotiation and in Stage 1 and Stage 2 to gain a deeper understanding of the effects of talk on outcomes.

\subsection{Variables}

First, we present the dependent variables. Second, we describe the coding of the communication within the bargaining transcripts. Specifically, we describe the three talk variables paralleling the theoretical mechanisms through which communication may affect outcomes - talk about fairness; talk about competitive logic; and pure social talk.

Dependent Variables. We present analyses predicting two types of dependent variables: (1) the distance between an equal split of available funds and the actual distribution of resources (geometric distance from equal split) and (2) whether bargaining concludes with a precisely equal division of available funds (equal split). An equal split outcome in a three-way agreement results in each of the three players taking $1 / 3$ of the available resources (400 points), or $133^{1 / 3}$ points each. ${ }^{4}$ To calculate the geometric distance between an equal split and the actual distribution in a three-way agreement, let the actual payoff of a single party $i$ be denoted by $P_{i}$. The general equation for the geometric distance from equal split in a three-way agreement, normalized to lie between zero and one, is calculated: ${ }^{5}$

\footnotetext{
${ }^{4}$ Because 400 is not a multiple of 3, we count any deal giving 133 to two of the parties and 134 to the third as an equal split.

${ }^{5}$ For example, if the agreement in a given game allocated 140 points for player A, 130 points for player B, and 130 points for player $\mathrm{C}$, then the geometric distance between that outcome and an equal split outcome would be:

Geometric Distance from Equal $=\sqrt{(140 / 400-1 / 3)^{2}+(130 / 400-1 / 3)^{2}+(130 / 400-1 / 3)^{2}}=0.02$
} 


$$
\sqrt{\left(P_{a} / 400-1 / 3\right)^{2}+\left(P_{b} / 400-1 / 3\right)^{2}+\left(P_{c} / 400-1 / 3\right)^{2}}
$$

In games that involve Stage 1 and Stage 2 agreements, we also measure the geometric distance from equal of the Stage 1, two-way division of surplus. An equal split in Stage 1 gives half of the divided surplus to each of the involved parties. Let the Stage 1 payoff of a single party $i$ be denoted by $P_{S 1, i}$. For example, if players A and B are included in the Stage 1 two-way deal, the normalized geometric distance from an equal split of the Stage 1 outcome is calculated: ${ }^{6}$

$$
\begin{aligned}
& \text { geometric distance from } \\
& \text { equal of Stage } 1 \text { division }
\end{aligned}=\sqrt{\left(P_{S 1, a} /\left(P_{S 1, a}+P_{S 1, b}\right)-1 / 2\right)^{2}+\left(P_{S 1, b} /\left(P_{S 1, a}+P_{S 1, b}\right)-1 / 2\right)^{2}}
$$

If a second stage of bargaining takes place after an initial two-way agreement, the distance from equal in Stage 2 depends on the payoffs of the two remaining players only. The Stage 2 outcome measure, similar to the general outcome measure described above, quantifies the geometric distance between the final division of resources and an equal division of the available resources between the parties. An equal division in Stage 2 would give half of the available pie to each of the remaining two players. The available pie in Stage 2 for all games is 400 points minus the payoff to the party acquired in Stage 1 . In the case in which player $\mathrm{C}$ has already been acquired in Stage 1, the normalized geometric distance from an equal split of the Stage 2 outcome is calculated: ${ }^{7}$

$$
\sqrt{\left(P_{a} /\left(400-P_{c}\right)-1 / 2\right)^{2}+\left(P_{b} /\left(400-P_{c}\right)-1 / 2\right)^{2}}
$$

${ }^{6}$ For example, imagine player A acquired player B for 100 points in Stage 1, treatment 1 . This means player B's Stage 1 (and final) payoff is 100 points, and because firms A and B are worth 300 together, A's payoff would be 200 if the game ended at this point. The normalized geometric distance between that Stage 1 outcome and an equal split would be:

Geometric Distance from Equal of Stage 1 Division $\quad=\sqrt{(200 / 300-1 / 2)^{2}+(100 / 310-1 / 2)^{2}}=0.23$

${ }^{7}$ For example, imagine player B acquired player C for 90 points in Stage 1, treatment 1 . This leaves available resources of $(400-90=310)$ for division between firm BC and firm A in Stage 2. If firm BC then acquired firm A for 120 points, the payoff to B is $(310-120=190)$. The normalized geometric distance between the Stage 2 outcome and an equal split would be:

Geometric Distance from Equal Stage 2 Division

$$
=\sqrt{(120 / 310-1 / 2)^{2}+(190 / 310-1 / 2)^{2}}=0.16
$$


Predictor variables: Content Analysis of Communication. Two of the current authors read through several transcripts to determine the distinct, substantive categories of communication present in the interactions. ${ }^{8}$ Four coding categories were relevant to the three mechanisms through which communication may affect the likelihood of equal payoffs in bargaining: talk about fairness; talk about competitive logic; and, as others have suggested before us, pure social talk (aggregation of personal revelations and chit-chat). Each message sent by one of the three parties was recorded as a separate "talk unit." Code definitions, along with examples of actual messages drawn from the transcripts, are presented in Table 2. Three independent raters then coded all of the messages. The agreement rate was $92.1 \%$ across all coding categories. When raters disagreed on a code, the majority opinion was recorded.

\begin{tabular}{|c|c|c|c|c|}
\hline $\begin{array}{c}\text { Communication } \\
\text { Variable }\end{array}$ & $\begin{array}{c}\text { Coding Category } \\
\text { (Single item rater } \\
\text { agreement rate) }\end{array}$ & & Coding Protocol & Examples from Transcripts \\
\hline Fairness Talk & $\begin{array}{l}\text { Fairness } \\
(74.4 \%)\end{array}$ & & $\begin{array}{l}\text { Use of the word "fair" or a synonym } \\
\text { Proposing or mentioning an equal division of } \\
\text { points between two or more players }\end{array}$ & $\begin{array}{l}\text { - "How about a more equitable } \\
\text { division of assets?” } \\
\text { - “do y'all wanna split 3-ways?” } \\
\text { - “25 for each of us is totally fair” }\end{array}$ \\
\hline $\begin{array}{l}\text { Competitive } \\
\text { Reasoning }\end{array}$ & $\begin{array}{c}\text { Competitive logic } \\
(96.1 \%)\end{array}$ & (1) & $\begin{array}{l}\text { Comments in which a player states his/her } \\
\text { underlying rationale for a move or questions the } \\
\text { underlying rationale of another player } \\
\text { Explanations of thoughts, plans or actions or } \\
\text { questions about the thoughts, plans or actions of } \\
\text { another player } \\
\text { Comments fitting } 1 \text { and/or } 2 \text { were excluded if } \\
\text { the talk unit was also coded as fairness talk }\end{array}$ & $\begin{array}{l}\text { - “yeah, but what are you going to } \\
\text { get with B?" } \\
\text { - "but the point is, you're not in much } \\
\text { of a position to bargain" } \\
\text { - "you guys can't make more than } \\
100 \text { if i'm not a part of the merger." }\end{array}$ \\
\hline \multirow{2}{*}{ Social Talk } & $\begin{array}{l}\text { Personal } \\
\text { revelations } \\
(93.4 \%)\end{array}$ & & $\begin{array}{l}\text { Comments containing any non-task-related } \\
\text { discussion of one or more players' outside lives } \\
\text { Questions about aspects of other players' lives }\end{array}$ & $\begin{array}{l}\text { - “are you all undergrads?” } \\
\text { - "anybody got plans for } \\
\text { thanksgiving?” } \\
\text { - "I'm from Seattle." }\end{array}$ \\
\hline & $\begin{array}{c}\text { Chit-chat } \\
(87.2 \%)\end{array}$ & & $\begin{array}{l}\text { Friendly or neutral conversation that is not task- } \\
\text { related } \\
\text { Social filler that does not also serve a task } \\
\text { function; chit chat is purely social }\end{array}$ & $\begin{array}{l}\text { - "hello" } \\
\text { - "everyone enjoying themselves so } \\
\text { far?" }\end{array}$ \\
\hline
\end{tabular}

We created frequency counts of Fairness Talk and Competitive Reasoning by summing the total number of talk units coded for a given category within a single three-party bargaining game. We added the frequency counts for personal revelations and chit chat to create a measure of Social Talk. For all three measures, the raw frequencies were normalized by dividing each of the frequency counts by the total number of talk units in a given game. A z-transformation on these ratios resulted in three predictor

\footnotetext{
${ }^{8}$ A full description of inductively derived coding categories is available from the authors upon request.
} 
variables, which we refer to as Social Talk, Fairness Talk and Competitive Reasoning. If communication works through the emergence of a dominant frame for an interaction, the distribution of available resources should vary with Fairness Talk and Competitive Reasoning. In contrast, if the mere presence of communication affects outcomes, Social Talk or the aggregation of all talk should predict the equality of resource distribution. Table 3 provides descriptive information about the raw data and correlations between our transformed communication variables.

Table 3. Descriptive statistics about raw variables and correlations between transformed talk

\begin{tabular}{lcccc} 
& $\begin{array}{c}\text { Non-Standard- } \\
\text { ized Mean }\end{array}$ & $\begin{array}{c}\text { Non-Standardized } \\
\text { Standard Deviation }\end{array}$ & $\begin{array}{c}\text { Competitive } \\
\text { Reasoning }\end{array}$ & $\begin{array}{c}\text { Fairness } \\
\text { Talk }\end{array}$ \\
\cline { 2 - 5 } Competitive Reasoning & 3.56 & 4.80 & & \\
Fairness Talk & 0.99 & 1.78 & 0.04 & \\
Social Talk & 4.02 & 15.40 & $-0.21 * * *$ & -0.04 \\
\hline$* p<0.1, * * p<0.05, * * * p$ & & & &
\end{tabular}

To account for the different paths to agreement discussed above, in addition to creating gamelevel talk variables, we divided the talk units in each bargaining session into two periods - "Stage 1 talk" and "Stage 2 talk." Stage 1 talk includes all talk units that occur before the first agreement, whether that agreement is a two-way or three-way agreement. In the subset of 101 games that ended in direct threeway deals and the four games that ended in impasse, Stage 1 talk subsumes all talk units in the entire interaction. Stage 2 talk includes all talk units taking place after an initial two-way agreement was reached, i.e., the communication between the two parties remaining after the first two-way deal. This resulted in three z-transformed variables for each type of communication, e.g., Fairness Talk, Fairness Talk in Stage 1, and Fairness Talk in Stage 2.

\subsection{Study 1 Results}

Table 4 provides summaries of payoffs. The table reports the percentage of equal 3-way splits and the average geometric distance from an equal division realized across all three parties' payoffs at the end of the bargaining session (given by equation (1) above), across different paths to agreement. 
Table 4. Average geometric distances between outcomes and equal divisions of available resources across paths of agreement and \% of Equal 3-Way Splits.

\begin{tabular}{lcccc}
\hline & Direct 3-Way & 3-Way Following 2-Way & 2-Way Only & No Agreement \\
\cline { 2 - 5 } Avg Geometric Distance from Equal & 0.02 & 0.13 & 0.28 & 0.12 \\
\% of Equal 3-Way Splits & $57 \%$ & $1 \%$ & $0 \%$ & $0 \%$ \\
$\mathbf{N}$ & 101 & 75 & 14 & 4 \\
\hline
\end{tabular}

We ran a series of analyses to assess the impact of endogenous communication on payoffs in multiparty bargaining. In the first set of regressions, we evaluate the effects of overall Fairness Talk, Competitive Reasoning and Social Talk on the final division of available resources in all 194 negotiations, ignoring takeover dynamics. We then turn to an examination of the subset of 89 observations in which there was an initial two-way agreement leading to two stages of negotiation. In all analyses presented in this section, we control for treatment with dummy variables (Treatment 6 omitted). We explore effects by treatment in our robustness analyses. Participants in our experiment took part in multiple bargaining sessions in the same treatment group, introducing the possibility of learning. We therefore control for possible learning effects in all of our analyses by including a variable indicating the round (1-5) in which bargaining took place. Results indicate that learning was not a significant factor in bargaining outcomes.

Effects of talk on final agreements. An increase in the relative frequency of Fairness Talk significantly reduces the geometric distance between the realized outcome and an equal division of available resources (see Table 5, Model 1). Neither overall Social Talk nor overall Competitive Reasoning has a significant effect on the distance variable. The frequency of Social Talk and Fairness Talk both increase the odds of an equal split of available resources (Model 2). 
Table 5. Parameter estimates (standard errors in parentheses), approximate p-values, and associated goodness-of-fit statistics for regression models (robust OLS, Model 1 and logistic, Model 2) that describe the relationship between the type of talk and the equality of final division of surplus.

\begin{tabular}{lcl}
\hline & \multicolumn{2}{c}{ Dependent Variable } \\
\cline { 2 - 3 } & Geometric Distance from Equal & Equal Split \\
\hline Competitive Reasoning & $\mathrm{N}=194$ & Model 2 \\
& 0.006 & $\mathrm{~N}=154^{\dagger}$ \\
Fairness Talk & $(0.007)$ & 0.010 \\
& $-0.013^{* *}$ & $(0.221)$ \\
Social Talk & $(0.005)$ & $0.623^{* *}$ \\
& -0.007 & $(0.260)$ \\
Treatment 1 & $(0.004)$ & $0.531^{* *}$ \\
& $0.137^{* * *}$ & $(0.249)$ \\
Treatment 2 & $(0.014)$ & $($ dropped) \\
Treatment 3 & $0.072^{* *}$ & -0.804 \\
Treatment 5 & $(0.028)$ & $(0.521)$ \\
& $0.051^{* * *}$ & $-1.45^{* * *}$ \\
Round & $(0.017)$ & $(0.543)$ \\
& $0.039^{* *}$ & $-1.23^{* *}$ \\
\hline $\mathbf{R}^{\mathbf{2}}$ or Pseudo $\mathbf{R}^{\mathbf{2}}$ & $(0.016)$ & $(0.495)$ \\
\hline
\end{tabular}

Key: ${ }^{*} \mathrm{p}<.1 ; * * \mathrm{p}<.05 ; * * * \mathrm{p}<.01$

${ }^{\dagger}$ All 40 games in treatment 1 were dropped by the logistic regression because that treatment condition perfectly predicts an unequal division of surplus.

Effects of Talk on Stage 1 and Stage 2 agreements. To explore the effects of talk in the subset of interactions that involved two stages of bargaining, we analyze the subset of 89 interactions in which two firms merged initially. Stage 1 talk predicts the geometric distance from equal of the two-way, Stage 1 agreements: more Competitive Reasoning early in bargaining leads to less equal payoffs in the initial twoparty agreements, while more Fairness Talk leads to more equal payoffs (see Table 6, Model 3). In Stage 2, Fairness Talk brings the parties closer to equal payoffs, but Stage 2 Competitive Reasoning and Social Talk have no effect (Model 4). ${ }^{9}$

\footnotetext{
${ }^{9}$ We ran an additional model with a dummy variable controlling for those deals that closed without a three-way agreement. The additional variable had no effect on the direction or significance of the talk variables.
} 


\begin{tabular}{|c|c|c|}
\hline & \multicolumn{2}{|c|}{ Dependent Variable } \\
\hline & $\begin{array}{l}\text { Geometric Distance from } \\
\text { Equal of Stage } 1 \text { Division }\end{array}$ & $\begin{array}{c}\text { Geometric Distance from Equal } \\
\text { of Stage } 2 \text { Division }\end{array}$ \\
\hline & $\begin{array}{l}\text { Model 3 } \\
\mathrm{N}=89 \\
\end{array}$ & $\begin{array}{l}\text { Model } 4 \\
\mathrm{~N}=89 \\
\end{array}$ \\
\hline Competitive Reasoning in Stage 1 & $0.043 * * *$ & \\
\hline Fairness Talk in Stage 1 & $-0.037 * *$ & \\
\hline Social Talk in Stage 1 & -0.001 & \\
\hline Competitive Reasoning in Stage 2 & & 0.018 \\
\hline Fairness Talk in Stage 2 & & $-0.039 * * *$ \\
\hline Social Talk in Stage 2 & & -0.004 \\
\hline$\overline{\text { treatment } 1}$ & 0.000 & $0.114^{*}$ \\
\hline treatment 2 & $0.161 *$ & 0.158 \\
\hline treatment 4 & 0.044 & 0.027 \\
\hline treatment 5 & 0.062 & 0.043 \\
\hline round & 0.006 & -0.005 \\
\hline $\mathbf{R}^{2}$ & 0.177 & 0.157 \\
\hline
\end{tabular}

Key: ${ }^{*} \mathrm{p}<.1 ; * * \mathrm{p}<.05 ; * * * \mathrm{p}<.01$

We ran a number of analyses to begin exploring the possible causal relationship between talk and offers/outcomes in Study 1. Because offers and communication occur simultaneously in Study 1, it is difficult to observe whether talk drives offers or vice versa. Ideally, we would be able to look at the effect of pre-offer talk on first offers, but little talk preceded the first offer in most bargaining sessions. We do find that talk in Stage 1 predicts the average geometric distance from equal of Stage 2 offers (see Table 7, Model 5). Specifically, talk about Competitive Reasoning increases the geometric distance from equal of Stage 2 offers, while Fairness Talk decreases it. In contrast, the geometric distance from equal of offers made during Stage 1 has no effect on the amount of Competitive Reasoning, Fairness Talk, or Social Talk in Stage 2 (Models 6 - 8). This evidence suggests talk may have a priming effect that alters the course of offers, while offers appear to have no impact on talk. Study 2 tests this causal relationship directly. 
Table 7. Parameter estimates (standard errors in parentheses), approximate p-values, and associated goodness-of-fit statistics for a series of robust OLS regression models that attempt to answer the question of whether talk drives offers or visa versa.

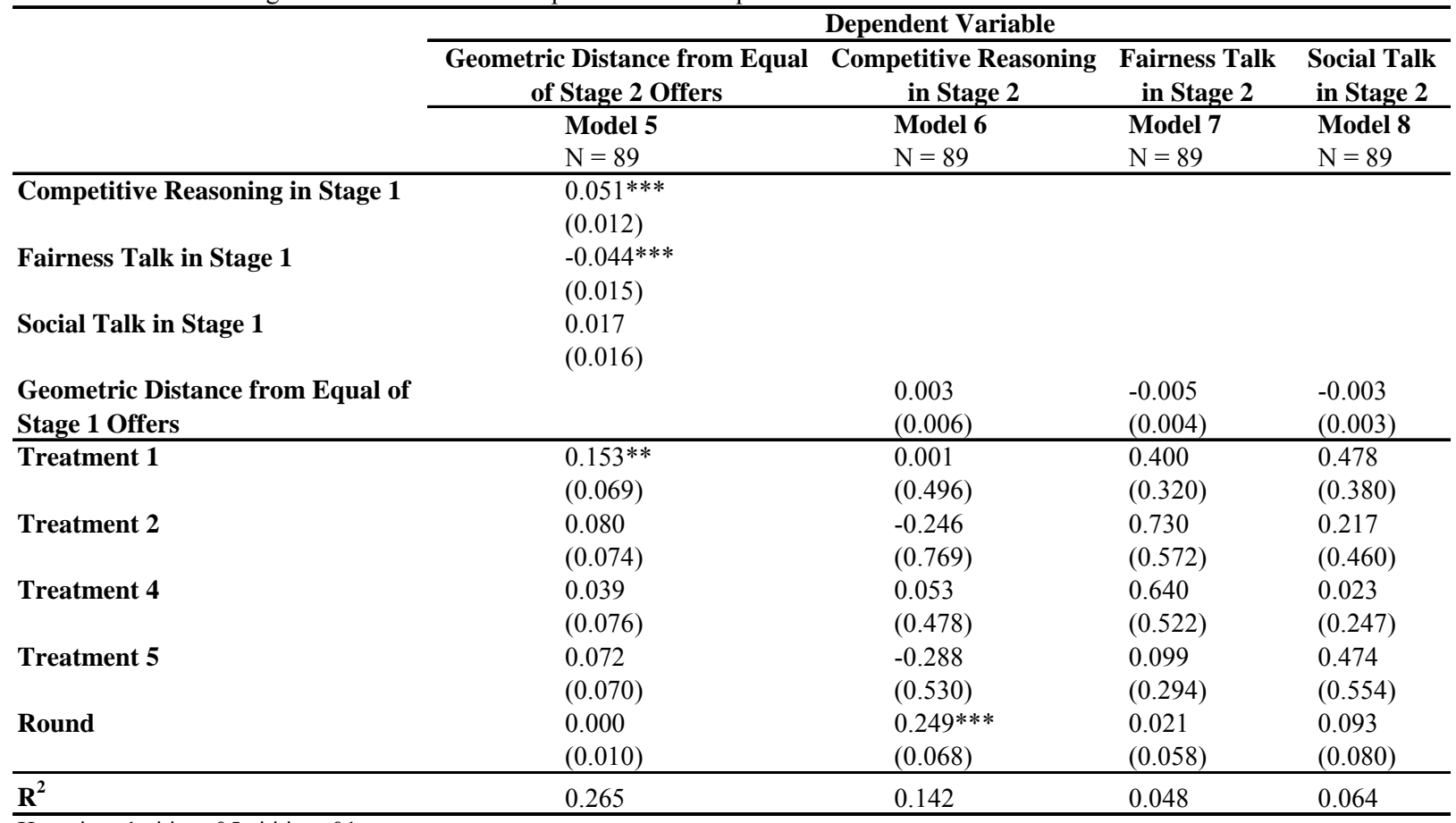

Key: $* \mathrm{p}<.1 ; * * \mathrm{p}<.05 ; * * * \mathrm{p}<.01$

\subsection{Robustness checks.}

Before concluding that talk is priming people for certain types of distributions, it is important to address alternative explanations for our results. First, we test whether the effects are driven by games in which equal split distribution is predicted in equilibrium. We then look at the possibility that our results reflect individual "types". 10

We reran all of our regressions excluding the two treatments (2 and 6$)$ in which the best fitting equilibrium prediction is equivalent to an equal division of available resources. Our findings are qualitatively the same when treatments 2 and 6 are dropped from the analyses, although the statistical significance of some coefficients on our talk variables is reduced slightly in some cases by the reduction in sample size.

It may be that talk is a byproduct of player "types." Fehr and Schmidt (1999) show that a fraction of players who care about fairness can drive bargaining outcomes toward equal distributions, while a

\footnotetext{
${ }^{10}$ Specific findings and statistics from all of the sensitivity analyses are available upon request. We report primarily overall effects here.
} 
fraction of "selfish" players can drive outcomes toward unequal, competitive payoffs. If certain players are prone to certain types of talk, any effects of talk on payoffs could be spurious. The fact that each participant played the same role (A, B or C) multiple times allows us to address this alternative explanation. For each of our five treatments and each of our three roles, we ran a one-way analysis of variance to test whether outcomes involving the same player are more similar to one another than outcomes involving different players in the same role. Only one of the fifteen F-tests for the equality of within-player means reached significance at the $10 \%$ level. We also ran Kruskal-Wallis non-parametric tests of the equality of populations on each player type and treatment. These tests yielded similar results; one test was significant at the 5\% level and another at the $10 \%$ level. These results suggest negligible individual effects on payoff distribution in our experiment.

Past research suggests that social talk, or even the mere presence of talk, has a positive effect on social awareness and cohesion, which may lead to more equal distribution of surplus (Sally, 1995). We, therefore, ran a number of additional robustness checks to distinguish between the mere presence or frequency of talk and the content of that talk. Thirty of the 194 games involved no informal communication, i.e., no text messages were exchanged through the chat box. The addition of a dummy variable for whether or not a bargaining game included any talk does not meaningfully change any of our results. The dummy variable is never significant, and while the significance of some of our findings is reduced by the inclusion of this variable, our results remain qualitatively similar. As an additional check, we added a control for the number of messages sent during bargaining and repeated all of our analyses. This did not change any of our findings in a notable way, and the coefficient on this control variable was never significant. Finally, we reran all of our regressions excluding games in which no talk took place. None of our findings change qualitatively when the games without talk are eliminated from our analyses. These robustness checks strengthened our conclusion that the content of talk is more important than the amount or presence of talk during bargaining. 


\subsection{Summary}

Study 1 shows that different types of communication, specifically talk about fairness and talk about competitive logic, are associated with different final payoffs in multiparty bargaining. Fairness talk is associated with payoffs that are closer to an equal division of the available surplus, while competitive talk is associated with payoffs that are further from an equal division. In contrast, the mere presence of talk is not associated with the distribution of payoffs. In this study, both talk and offers were endogenous. Our tests of early talk's effects on later offers and early offers' effects on later talk suggest that talk is driving offers rather than the reverse. In Study 2, we ran two experimental conditions involving different types of talk, allowing us to directly test the hypothesis that talk drives outcomes.

\section{Study 2}

\subsection{Experimental Design}

Study 2 was designed to test the hypothesis that pre-game communication about fairness drives parties toward a more equal division of available surpluses than pre-game communication about competitive reasoning. By randomly assigning subjects to a communication treatment - either Fairness Talk or Competitive Reasoning - we ensure that the type of talk they engage in prior to a negotiation is exogenous and that talk drives offers rather than vice versa.

\subsection{Summary of Laboratory Protocol ${ }^{11}$}

We test our hypothesis using a three-party bargaining game similar to that used in Study 1. We employ a single treatment (see Treatment 4 in Table 1), selected because it resulted in the highest variance in the geometric distance from an equal distribution of final payoffs in Study 1. Subjects were randomly assigned to one of two talk treatments in which we manipulated the type of pre-play communication.

One hundred twenty-six members of a standing subject pool participated. Each participant was randomly assigned to one role within one session and played three rounds within a single communication treatment. This resulted in 126 observations of three-party bargaining games. No participant encountered

\footnotetext{
${ }^{11}$ More information on the laboratory protocol including the instructions is available on request from the authors.
} 
the same player in more than one round and the number of rounds was not announced. Subjects were paid based on their earnings in a single, randomly selected round (US\$0.11 for each point earned), plus a base rate of US\$15. Actual incentive pay ranged from US\$6 to US\$26.

The three players communicated via a single screen interface similar to that used in Study 1. A two minute pre-game communication period containing the talk manipulation preceded the three-minute period in which free-flow communication, offers and deals were possible. During the pre-game communication period, each player was required to select and send a minimum of five different messages to the other two players from a pre-set drop down menu, ensuring that a minimum of communication took place before the first offer. Players could choose to send additional messages from the drop-down menu until the two minutes were over. Players then proceed to a three-minute full-communication bargaining game as in Study 1. The messages in the drop-down menus were taken from actual communication in Study 1. In the Fairness Talk treatment, subjects received a drop-down menu composed of 13 messages unanimously coded as Fairness Talk in Study 1. In the Competitive Reasoning treatment, subjects received a drop-down menu composed of 13 messages unanimously coded as Competitive Reasoning Talk. Drop-down menus in both treatments included four messages unanimously coded as Chit-Chat (Social Talk). Table 8 presents a list of the messages in the drop-down menus in each treatment. In the experiment, the messages in both treatments were randomly ordered.

\begin{tabular}{|c|c|}
\hline Contents of Fairness Drop-Down Menu & Contents of Competitive Reasoning Drop-Down Menu \\
\hline An even split? & This is a competition. \\
\hline Don't be bold, be fair and collaborative. & Since I am in a better position I should benefit more. \\
\hline Equal money! & The way to ultimately maximize is that one person will end up making more than the \\
\hline I would rather be fair. & other two. \\
\hline I'll be fair to you. & I just would like to make more money. \\
\hline Our best bet is to split this three ways and get it over & It's in your best interest to get as much $\$$ as you can. \\
\hline with. & $\mathrm{A}$ and $\mathrm{B}$ are in the stronger position, $\mathrm{C}$. \\
\hline Split or quit! & The stronger players ought to have the larger piece of the pie. \\
\hline That's fair. & We are all out for our best interest, I'm not trying to be the philanthropist here. \\
\hline The only "fair" way to do it is to split the bonus. & We have unequal bargaining power. \\
\hline We have to be fair, ok? & Says who that you're in the better position? \\
\hline We should be even. & We need to merge in order to reap the benefits. \\
\hline We will all be better off if we merge fairly. & It's not about winning, it's about making as much as possible. \\
\hline What's wrong with everyone getting the same? & A three-way deal is the way to make the most money total. \\
\hline $\mathrm{Hi}$ & $\mathrm{Hi}$ \\
\hline Howdy & Howdy \\
\hline Yes & Yes \\
\hline Good call. & Good call. \\
\hline
\end{tabular}




\subsection{Variables and Analyses}

Our outcome variables are identical to a subset of those described in Section 3.4. First, we test the effects of our communication treatments on the geometric distance between an equal split of available funds and the actual distribution of resources in the final payoffs (see equation (1)). Second, we test the effects of the communication treatments on the likelihood of an exact equal split of available surplus.

\subsection{Results and discussion}

Subjects in multiparty bargaining who engage in pre-game Fairness Talk divide the surplus more equally than subjects who engage in pre-game Competitive Reasoning talk. The average normalized geometric distance from an equal division of surplus for observations in the fairness treatment is significantly lower than in the competitive reasoning treatment (see Table 9). In addition, the proportion of equal splits in the fairness treatment is significantly higher than in the competitive reasoning treatment (see Table 9). The results of this study confirm that our findings from Study 1 hold when the type of talk available to parties in a negotiation is varied exogenously and when this talk occurs before offers are exchanged. Notably, the results hold even though the manipulated talk was followed by a three minute period of unrestricted, freeflow communication and offers.

\begin{tabular}{lcccc}
\hline Table 9. Results from Study 2. & \multicolumn{4}{l}{} \\
\hline & $\begin{array}{c}\text { "Fair" } \\
\text { Treatment }\end{array}$ & $\begin{array}{c}\text { "Competitive" } \\
\text { Treatment }\end{array}$ & Statistical Test & P-Value \\
\cline { 2 - 5 } Avg Geometric Distance from Equal & 0.09 & 0.11 & one-sided t-test & $<.05$ \\
Percentage of Equal 3-Way Splits & $(0.08)$ & $(0.08)$ & chi2-test & $<.001$ \\
$\mathbf{N}$ & $30 \%$ & $9 \%$ & & \\
\hline
\end{tabular}

\section{Conclusion}

Talk can unite, but it can also divide. In multiparty bargaining, communication can focus parties on a fair distribution of resources, but it can also focus parties on a competitive distribution of resources. The 
dominant logic in the discussions at the onset of interaction - be it fairness or competition - strongly influences the equality of payoffs even in complex, full-information multiparty bargaining.

Across five different game parameters in Study 1, increases in the relative frequency of talk about fairness are associated with payoffs closer to an equal split. Talk about competitive reasoning has the opposite effect, driving payoffs away from an equal division, though these effects are less consistent than fairness talk effects. We placed no restrictions on communication in our first study, so any framing evolved endogenously. We tested causality in Study 2 by exogenously manipulating the type of pre-play communication. Again, we found that Fairness Talk led to more equal payoffs than Competitive Reasoning. The frame assumed in communication, whether assigned or emergent, significantly affects payoffs. These findings are reminiscent of research in social psychology and organizational behavior on "negotiated belief structures" (Walsh and Fahey, 1986), "conflict frames" (Pinkley, 1990), and "logics of exchange" (McGinn and Keros, 2002; Uzzi, 1999).

Our results add critical insights to our understanding of communication's role in multiparty bargaining. A view of communication as increasing social awareness (Hoffman et al., 1996; McGinn and Croson 2004; Sally 1995) may be too simplistic to explain bargaining outcomes in multiparty settings. The mere presence of communication did not materially affect payoff distributions in Study 1, nor did pure social talk. In multiparty bargaining, as in two-party bargaining, communication may work in part through social awareness and in part by allowing players to threaten to walk away. Communicating the willingness to walk away, in conjunction with loss aversion by stronger players, may help weaker players convince stronger players to move toward a more equal split of the available surplus, but it also permits strong players to threaten weak players.

In a competitive, multiparty game, communication may play a more nuanced role than observed in simpler bargaining contexts. Communication in our setting allows two parties to create a coalition, effectively forcing the third party into an agreement. In competitively framed negotiations, this may involve the stronger parties "ganging up" on the weakest party, while in fairness framed bargaining, this may involve the weaker parties "ganging up" on the strongest. 
The communication in our experiments was carried out through an electronic chat room. Past research arguing for the social closeness effects of communication on bargaining outcomes has shown that face-to-face communication heightens interpersonal awareness much more than communication across other media (McGinn and Keros, 2002; Valley, Moag and Bazerman, 1998). It may be that social talk would have had more impact on payoffs if our bargaining experiments had been carried out face-toface. The same may be true for the framing effects of fairness talk or competitive reasoning. Future research could explore whether face-to-face communication simply heightens the social closeness effects of talk overall, or whether the medium interacts with the content of the communication to influence framing and outcomes.

The path to equality is paved with talk of fairness, while the path away from equality is paved with talk of competition. Equilibrium models of bargaining have begun to incorporate fairness considerations. To improve their predictive power, they should incorporate the ways in which the content of communication can prime participants and thereby affect behavior and outcomes. 
Appendix: Sample Screen from Study 1

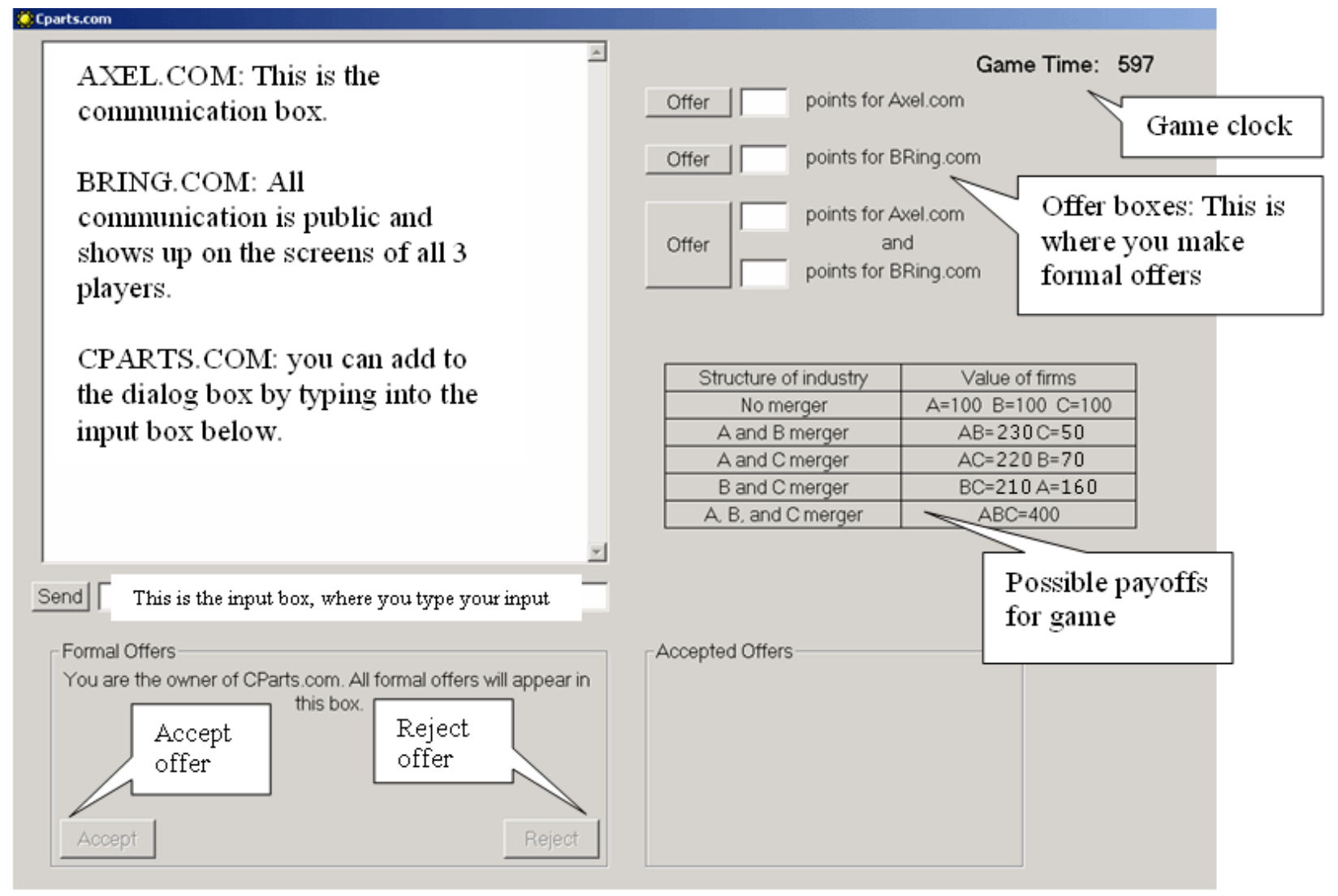

In the sample screen shown above, the white box in the upper left corner displays the communication between the three parties. The input field below this box can be used to enter a new message, which will be displayed in the public communication box. In the upper right corner players can make offers either to one of the other parties or to both of them simultaneously. The possible payoffs for this specific game are shown on the right side of the screen. In the lower left corner, buttons to accept or reject an offer are displayed. 


\section{References}

Blume, A., A. Ortmann, 2007. The effects of costless pre-play communication: Experimental evidence from games with Pareto-ranked equilibria. Journal of Economic Theory. 132, 274-290.

Bohnet, I., B.S. Frey, 1999. The sound of silence in prisoner's dilemma and dictator games. Journal of Economic Behavior and Organization. 38, 43-57.

Bolton, G.E., J. Brosig, 2007. How coalitions get built: Evidence from an extensive form coalition game with renegotiation and externalities. Working paper, Smeal College of Business, Pennsylvania State University, University Park, PA.

Bolton, G.E., K. Chatterjee, K.L. McGinn, 2003. How communication links influence coalition bargaining: A laboratory investigation. Management Science 49(5) 583-598.

Bolton, G.E., A. Ockenfels, 2000. ERC: A theory of equity, reciprocity, and competition. American Economic Review 90(1) 166-193.

Brams, S.J., A.D. Taylor, 1996. Fair Division: From Cake-Cutting to Dispute Resolution. Cambridge University Press.

Charness, G., M. Dufwenberg, 2006. Promises and partnership. Econometrica. 74, 1579-1601.

Crawford, V., 1990. Explicit Communication and Bargaining Outcomes, American Economic Review (P\&P) 80(2), 213-219.

Crawford, V., 1998. A Survey of Experiments on Communication via Cheap Talk. Journal of Economic Theory. 78, 286-298.

Crawford, V., J. Sobel, 1982. Strategic information transmission. Econometrica. 50(6) 1431-1451.

Croson, R., A. Gomes, K.L. McGinn, M. Nöth, 2004. Mergers and acquisitions: An experimental analysis of synergies, externalities and dynamics. Review of Finance. 8(4), 481-514.

Demichelis, S., J.W. Weibull, 2008. Language, Meaning, and Games: A Model of Communication, Coordination, and Evolution. American Economic Review. 98, 1292-1311.

Farrell, J., 1988. Communication, coordination and Nash equilibrium. Economics Letters. 27, 209-214.

Farrell, J., M. Rabin, 1996. Cheap talk. Journal of Economic Perspectives. 10, 103-118.

Fehr, E., K.M. Schmidt, 1999. A theory of fairness, competition, and cooperation. Quarterly Journal of Economics 114(3) 817-868.

Frey, B., S. Meier, 2004. Social comparisons and pro-social behavior: Testing" conditional cooperation" in a field experiment. American Economic Review. 94(5) 1717-1722.

Gomes, A. 2005. Multilateral contracting with externalities. Econometrica 73(4) 1329-1350. 
Güth, W., P. Ockenfels, R. Tietz, 1990. Distributive justice versus bargaining power - Some experimental results, S.E.G. Lea, P. Webley, B.M. Young (eds), Applied Economic Psychology in 1990s, Washington Singer Press, Exeter, Vol. 2, 840-860.

Higgins, E.T., J.A. Bargh, 1987. Social perception and social cognition. Annual Review of Psychology $38,369-425$.

Hoffman, E., K. McCabe, V.L. Smith, 1996. Social distance and other-regarding behavior in dictator games. American Economic Review. 86(3) 653-660.

Kachelmeier, S. J., Towry, K. L., 2002. Negotiated Transfer Pricing: Is Fairness Easier Said than Done? Accounting Review 77(3), 571-593.

Kahneman, D., J. L. Knetsch, R. Thaler, 1986. Fairness as a constraint on profit seeking: Entitlements in the market. American Economic Review. 76(4), 728-741.

Liberman, V., S.M. Samuels, L. Ross. 2004. The name of the game: predictive power of reputations versus situational labels in determining prisoner's dilemma game moves. Personality and Social Psychology Bulletin 30(9), 1175-1185.

Lopomo, G., E.A. Ok, 2001. Bargaining, Interdependence, and the Rationality of Fair Division. RAND Journal of Economics 32(2), 263-283.

Marshall, A., 1969. The Principles of Economics. Macmillan, London: English Language Book Society.

McGinn, K.L., R. Croson. 2004. What do communication media mean for negotiations? A question of social awareness. M. Gelfand, J. Brett, eds. Culture and negotiations: Integrative approaches to theory and research. Stanford University Press, Palo Alto, CA, 334-349.

McGinn, K.L., A.T. Keros, 2002. Improvisation and the logic of exchange in embedded negotiations. Administrative Science Quarterly. 47, 442-473.

Nash, J., 1951. Non-cooperative games. Annals of Mathematics. 54, 286-295.

Orbell, J. M., A.J.C. van de Kragt, R.M. Dawes, 1988. Explaining discussion-induced cooperation. Journal of Personality and Social Psychology. 54, 811-819.

Pinkley, R.L., 1990. Dimensions of conflict frame: Disputant interpretations of conflict. Journal of Applied Psychology 75(2), 117-126.

Prasnikar, V., A.E. Roth. 1992. Considerations of fairness and strategy: Experimental data from sequential games. Quarterly Journal of Economics 107(3), 865-888.

Rabin, M. 1990. Communication between rational agents. Journal of Economic Theory 51(1), 144-170.

Rabin, M. 1993. Incorporating fairness into game theory and economics. American Economic Review 83(5), 1281-1302.

Rabin, M., 1994. A Model of Pre-game Communication. Journal of Economic Theory. 63, 370-391. 
Robert, C., P.J. Carnevale. 1997. Group choice in ultimatum bargaining. Organizational Behavior \& Human Decision Processes 72(2) 256-279.

Roth, A.E., M.W.K. Malouf, 1979. Game-theoretic models and the role of information in bargaining. Psychological Review. 86, 574-594.

Sally, D., 1995. Conversation and Cooperation in Social Dilemmas: A Meta-Analysis of Experiments from 1958 to 1992 . Rationality and Society 7, 58-92.

Schmeidler, D., 1969. The nucleolus of a characteristic function game. SIAM Journal of Applied Mathematics 17(6), 1163-1170.

Shapley, L.S., 1953. A value for n-person games. H. Kuhn, A. Tucker (eds), Contributions to the Theory of Games. Princeton University Press, Princeton, NJ, 307-317.

Uzzi, B. 1999. Embeddedness in the making of financial capital: How social relations and networks benefit firms seeking financing. American Sociological Review 64(4), 481-505.

Valley, K.L., J. Moag, M.H. Bazerrman, 1998. 'A matter of trust': Effects of communication on the efficiency and distribution of outcomes. Journal of Economic Behavior and Organization 34(2), 211-238.

Valley, K.L., L. Thompson, R. Gibbons, M.H. Bazerman, 2002. How communication improves efficiency in bargaining games. Games and Economic Behavior. 38(1), 127-155.

Von Neumann, J., O. Morgenstern, 1953. Theory of Games and Economic Behavior. Princeton University Press, Princeton, NJ.

Walsh, J.P., L. Fahey, 1986. The role of negotiated belief structures in strategy making. Journal of Management. 12(3) 325-338.

Young, H. P., 1993. An Evolutionary Model of Bargaining. Journal of Economic Theory 59 (1), 145-168. 